\title{
The effect of the cholinergic anti- inflammatory pathway on collagen-induced arthritis involves the modulation of dendritic cell differentiation
}

\author{
Di Liu, Tong Li, Hui Luo, Xiaoxia Zuo, Sijia Liu* and Shiyao Wu*
}

\begin{abstract}
Background: The cholinergic anti-inflammatory pathway (CAP) has a strong anti-inflammatory effect on collageninduced arthritis (CIA), a classic animal model of rheumatoid arthritis (RA). However, the underlying immune regulatory mechanism remains unclear. Here, we investigated the effect of the CAP on arthritis development and the involvement of dendritic cells (DCs).

Methods: Forty DBA/1 mice were randomly divided into five groups: a control group (sham vagotomy+ phosphate-buffered saline; shamVGX+PBS), a CIA group (shamVGX+CIA + PBS), a vagotomy group (VGX + CIA + PBS), a GTS-21 (4 mg/kg) group (shamVGX+CIA + GTS-4), and a GTS-21 (8 mg/kg) group (shamVGX $+\mathrm{CIA}+\mathrm{GTS}-8$ ). The vagotomy group underwent left cervical vagotomy 4 days before arthritis induction, whereas the sham-vagotomy group underwent vagus nerve exposure. Mice were pretreated with GTS-21 by intraperitoneal injection on the day of surgery. The degree of arthritis was measured by using the arthritis score, hematoxylin and eosin staining, and TRAP (tartrate-resistant acid phosphatase) staining. Flow cytometry was used to detect the expression of CD80 and major histocompatibility complex II (MHC II) on CD11 $\mathrm{C}^{+} \mathrm{DCs}$ in the spleen. Luminex was used to detect the serum concentration of interleukin-6 (IL-6), tumor necrosis factor-alpha (TNFa), and IL-10. Immunohistochemistry was used to detect CD11c expression in the synovium. The effects of GTS-21 on DC differentiation and maturation were examined in vitro by treating bone marrowderived DCs with GTS-21 and assessing differentiation and maturation. Flow cytometry was used to analyze CD80 and MHC II expression on the surface of DCs.

Results: GTS-21 treatment ameliorated clinical arthritis in a mouse model of CIA in vivo, decreasing the secretion of pro-inflammatory cytokines in the serum and downregulating CD80 and MHC II expression on DCs in the spleen of CIA mice. GTS-21 treatment strongly suppressed the infiltration of DCs into the synovium. Vagotomy itself did not exacerbate the severity of arthritis in CIA mice. In vitro, GTS-21 (10 $\mu \mathrm{mol} / \mathrm{L})$ significantly downregulated CD80 and MHC II in bone marrow-derived immature DCs and this effect was blocked by the a7-nicotinic acetylcholine receptor antagonist methyllycaconitine (MLA). However, GTS-21 had no effects on mature DCs.
\end{abstract}

Conclusions: The present study provides new insight into the mechanism underlying the effects of the CAP on RA and indicates that the immunosuppressive effect of GTS-21 may be mediated by the inhibition of DC differentiation.

Keywords: Rheumatoid arthritis, Dendritic cells, Cholinergic anti-inflammatory pathway, GTS-21

\footnotetext{
* Correspondence: celialiu@csu.edu.cn; wushiyao1985@yeah.net

Department of Rheumatology and Immunology, Xiangya Hospital, Central

South University, Hunan Province, Changsha 410008, People's Republic of

China
}

(c) The Author(s). 2018 Open Access This article is distributed under the terms of the Creative Commons Attribution 4.0 International License (http://creativecommons.org/licenses/by/4.0/), which permits unrestricted use, distribution, and reproduction in any medium, provided you give appropriate credit to the original author(s) and the source, provide a link to the Creative Commons license, and indicate if changes were made. The Creative Commons Public Domain Dedication waiver (http://creativecommons.org/publicdomain/zero/1.0/) applies to the data made available in this article, unless otherwise stated. 


\section{Introduction}

Rheumatoid arthritis (RA) is a chronic autoimmune disease characterized by synovial inflammation and cartilage and bone destruction. Although the pathogenesis is unknown, it is believed that inflammatory cell infiltration into the synovium is the main cause of persisting synovitis [1]. Dendritic cells (DCs) are important innate immune cells and professional antigen-presenting cells that play an important role in immunologic priming. DCs contribute to the pathogenesis of RA. Mature DCs in the synovium and secondary lymphoid organs can present antigens to naïve $\mathrm{T}$ cells and induce $\mathrm{T}$-cell activation [2, 3]; DCs secrete inflammatory cytokines such as interleukin-12 (IL-12), IL-23, IL-6, tumor necrosis factor-alpha (TNF- $\alpha$ ), and IL-1 to induce Th1, Th2, and Th17 differentiation, aggravating the inflammation of the synovium [4-7]. In addition, DCs produce B cell-activating factor, thus promoting the proliferation of antibody-producing B cells [8]. Studies indicate that DC-based immunotherapy may be effective for the treatment of RA. In a mouse model of collagen-induced arthritis (CIA), DCs with tolerogenic characteristics suppressed the progression of established CIA [9-11]. DC differentiation into a tolerogenic state is an attractive tool to restore self-tolerance in RA and other autoimmune disorders [12]. Moreover, clinical trials confirmed that the strategy is safe, feasible, and acceptable [13, 14]. These data suggest that DCs are a promising target for the treatment of RA.

The cholinergic anti-inflammatory pathway (CAP) is an endogenous anti-inflammatory pathway that links the nervous system and the immune system via the vagus nerve [15]. Activation of the CAP can be achieved by vagus nerve stimulation or cholinergic agonists [16]. GTS-21, a classic cholinergic agonist, can bind to the $\alpha 7$ subunit of the nicotinic acetylcholine receptor ( $\alpha 7 \mathrm{nAChR})$ of inflammatory cells to induce an anti-inflammatory response [17]. A previous study showed that the CAP is involved in the reduction of inflammation in experimental sepsis, acute lung injury, ischemia/reperfusion injury, and pancreatitis [18].

Accumulating evidence indicates that the CAP suppresses inflammation in RA. Stimulation of nicotinic acetylcholine receptors attenuates CIA in mice, whereas knockdown of the $\alpha 7 \mathrm{nAChR}$ aggravates CIA [19]. Previous work from our group confirmed that the CAP inhibits arthritis development by regulating immune cells, such suppressing the TNF- $\alpha$-dependent inflammatory pathway in synoviocytes and Th1 cells, Th17 cell differentiation, and macrophage migration [20-24]. The $\alpha 7 \mathrm{nAChR}$ is also expressed on the surface of DCs [25]. However, the effects of CAP on DCs remain unclear in RA. Here, we investigated the anti-inflammatory effect of the cholinergic agonist GTS-21 on RA and examined the role of DCs.

\section{Materials and methods}

\section{Animals}

Five-week-old C57BL/6 J male mice and 5-week-old DBA/1 male mice were purchased from the Shanghai Institute of Experimental Animals. The mice were fed adaptively for 1 week. The experiment was approved by the Ethics Committee for Laboratory Animals of Central South University.

\section{Experimental groups}

Forty DBA/1 male mice were randomly divided into five groups: a control group (sham vagotomy + phosphate-buffered saline, sham VGX + PBS), a model group (sham VGX + PBS + CIA), a vagotomy group (VGX + PBS + CIA), a GTS-21 $4 \mathrm{mg} / \mathrm{kg}$ group (sham VGX + GTS-21 $4 \mathrm{mg} / \mathrm{kg}+$ CIA), and a GTS-21 $8 \mathrm{mg} / \mathrm{kg}$ group (sham VGX + GTS-21 $8 \mathrm{mg} / \mathrm{kg}+\mathrm{CIA})$. To block the CAP, mice in the vagotomy group underwent left cervical vagotomy 4 days before CIA induction, whereas the left vagus nerve was exposed but not cut in the sham operation group. To activate the CAP, mice received different doses of GTS-21 (4 and $8 \mathrm{mg} / \mathrm{kg}$ ) from 4 days before the induction of CIA to 45 days after the first immunization, and the other group received an equal volume of phosphate buffer by intraperitoneal injection at the same time points.

\section{$\mathrm{CIA}$ induction}

Bovine type II collagen (Chondrex, Redmond, WA, USA) was diluted to $2 \mathrm{mg} / \mathrm{mL}$ with $10 \mathrm{mM}$ acetic acid and emulsified with an equal volume of Freund's complete adjuvant (Chondrex). The CIA model mice were injected with $0.1 \mathrm{~mL}$ of fully emulsified bovine collagen intradermally at the tail base. At 21 days after the first immunization, CIA mice were injected with the same amount of bovine type II collagen emulsified with Freund's incomplete adjuvant (Chondrex) as the second immunization.

\section{Evaluation of arthritis}

Starting on the day of the second immunization, each digit and paw were assessed every 3 days by two investigators until day 45 . The arthritis index scoring criteria were as follows: 0 , normal; 1 , slight redness or swelling of the joint; 2, moderate swelling; 3, obvious swelling; and 4, severe swelling and inability to bear weight.

\section{Histopathological examination and immunohistochemistry}

Mice were sacrificed on day 45 . The joints were removed, fixed in formalin for $48 \mathrm{~h}$, decalcified in $10 \%$ ethylenediaminetetraacetic acid, and embedded in paraffin. The sections were stained with hematoxylin and eosin (HE) and tartrate-resistant acid phosphatase (TRAP) for 
histopathological analysis. The severity of inflammatory cell infiltration (grade 0-4) and synovial hyperplasia (grade $0-3$ ) were scored as previously described in joints of ankle and knee $[26,27]$. TRAP $^{+}$osteoclasts were counted manually in joints of the ankle and knee. The CD11c expression level in the synovium was examined with immunohistochemistry by using a rabbit antimouse CD11c antibody (1:200; Servicebio, Wuhan, China) in accordance with the instructions of the manufacturer. The integrated optical density (IOD) values of tissue sections in each group were measured by Image-Pro Plus 6.0 software (Media Cybernetics, Inc., Rockville, MD, USA) after tissue images were captured under an optical microscope $(100 \times)$. Five views were randomly selected to determine the positive IOD values and the mean of these values was considered the relative expression of CD11c [28, 29].

\section{Cytokine analysis}

Sera were collected from the blood of all mice on day 45; the content of cytokines (TNF-a, IL-6, and IL-10) was measured by using the mouse magnetic Luminex screening assay (R\&D Systems, Minneapolis, MN, USA).

\section{Analysis of DC phenotypes in the spleen}

On day 45, spleen single-cell suspensions were collected from the five groups of mice, filtered with a cell strainer, and stained with PerCP/Cy5.5 anti-mouse CD11c, PE anti-mouse CD80, APC anti-mouse I-A/I-E (major histocompatibility complex II, or MHC II), or the corresponding isotype control (BioLegend, San Diego, CA, USA) for $25 \mathrm{~min}$ at $4{ }^{\circ} \mathrm{C}$. After washing with wash buffer, cells were analyzed by using flow cytometry.

\section{Preparation of bone marrow-derived DCs}

Bone marrow-derived DCs (BMDCs) were generated from the tibias and femurs of 6-week-old male C57BL/6 J mice as described previously [30, 31]. Cells were cultured in complete RPMI 1640 medium (HyClone, part of GE Healthcare, Chicago, IL, USA) supplemented with $10 \%$ fetal bovine serum, $20 \mathrm{ng} / \mathrm{mL}$ recombinant mouse granulocytemacrophage colony-stimulating factor (rmGM-CSF), and $10 \mathrm{ng} / \mathrm{mL}$ rmIL-4 (PeproTech, Rocky Hill, NJ, USA) at a density of $5 \times 106$ cells $/ \mathrm{mL}$ in six-well plates. After 1 day, non-adherent cells were washed off and new complete medium supplemented with $10 \%$ fetal bovine serum, $20 \mathrm{ng} /$ $\mathrm{mL}$ rmGM-CSF, and $10 \mathrm{ng} / \mathrm{mL}$ rmIL- 4 was added. New complete medium and cytokines were added every 3 days. On day 6 of culture, immature BMDCs were collected. Immature BMDCs were matured by further culturing in the presence of $1 \mu \mathrm{g} / \mathrm{mL}$ lipopolysaccharide (Sigma-Aldrich, Munich, Germany) for $24 \mathrm{~h}$, and mature BMDCs were harvested.

\section{Phenotyping of BMDCs}

BMDCs prepared as described earlier were harvested and stained with PerCP/Cy5.5 anti-mouse CD11c, PE anti-mouse CD80, APC anti-mouse I-A/I-E (MHC II), FITC anti-mouse $\mathrm{F} 4 / 80$, or the corresponding isotype control (BioLegend) for $25 \mathrm{~min}$ at $4{ }^{\circ} \mathrm{C}$. After washing, cells were analyzed with flow cytometry. Data analysis was performed by using FlowJo software (Tree Star, Ashland, OR, USA), and the results were reported as mean fluorescence intensity.

\section{Statistical analysis}

Statistical analysis was performed with GraphPad Prism software (GraphPad Software, La Jolla, CA, USA). Data were expressed as the mean \pm standard deviation. Intergroup comparisons were performed by using one-way analysis of variance. If the data did not satisfy normal distribution, the rank sum test was used. A $P$ value of less than 0.05 was considered significant.

\section{Results}

GTS-21 attenuates the inflammatory response in CIA mice To determine whether the CAP regulates the inflammatory response in RA, the left vagus nerve was sectioned to inhibit the pathway, and GTS-21 was injected into the peritoneal cavity to activate the pathway 4 days before CIA induction. The degree of paw swelling was evaluated by using the arthritis index score every 3 days starting on day 21 after the first immunization. No paw swelling was observed in the control group, whereas the first signs of swelling appeared on day 24 in other groups. Joint swelling in the model and vagotomy groups reached a peak on days 42 and 39, respectively. The GTS-21 4 and $8 \mathrm{mg} / \mathrm{kg}$ groups showed mild joint swelling, and the arthritis scores were significantly lower than those in the model and vagotomy groups $(P<0.05)$ (Fig. 1a and b).

The ameliorating effect of GTS-21 on CIA was confirmed by HE staining and TRAP staining of joints. The model and vagotomy groups showed infiltration of numerous inflammatory cells, osteoclasts, and synovial hyperplasia in the ankle and knee joints compared with the control group. The abnormalities were significantly alleviated in CIA mice after administration of GTS-21 (4 and $8 \mathrm{mg} / \mathrm{kg}$ ) (Fig. 1c-h).

\section{GTS-21 reduces the levels of serum TNF- $a$ and IL- 6 , but not IL-10, in CIA mice}

To examine the effect of GTS-21 and vagotomy on inflammatory factors in the serum of DBA/ 1 mice, Luminex was used to detect the levels of IL- 6 , TNF- $\alpha$, and IL-10. The serum levels of TNF- $\alpha$ and IL-6 were significantly higher in the model and vagotomy groups than in the control group, whereas GTS-21 ( 4 and $8 \mathrm{mg} / \mathrm{kg}$ ) 


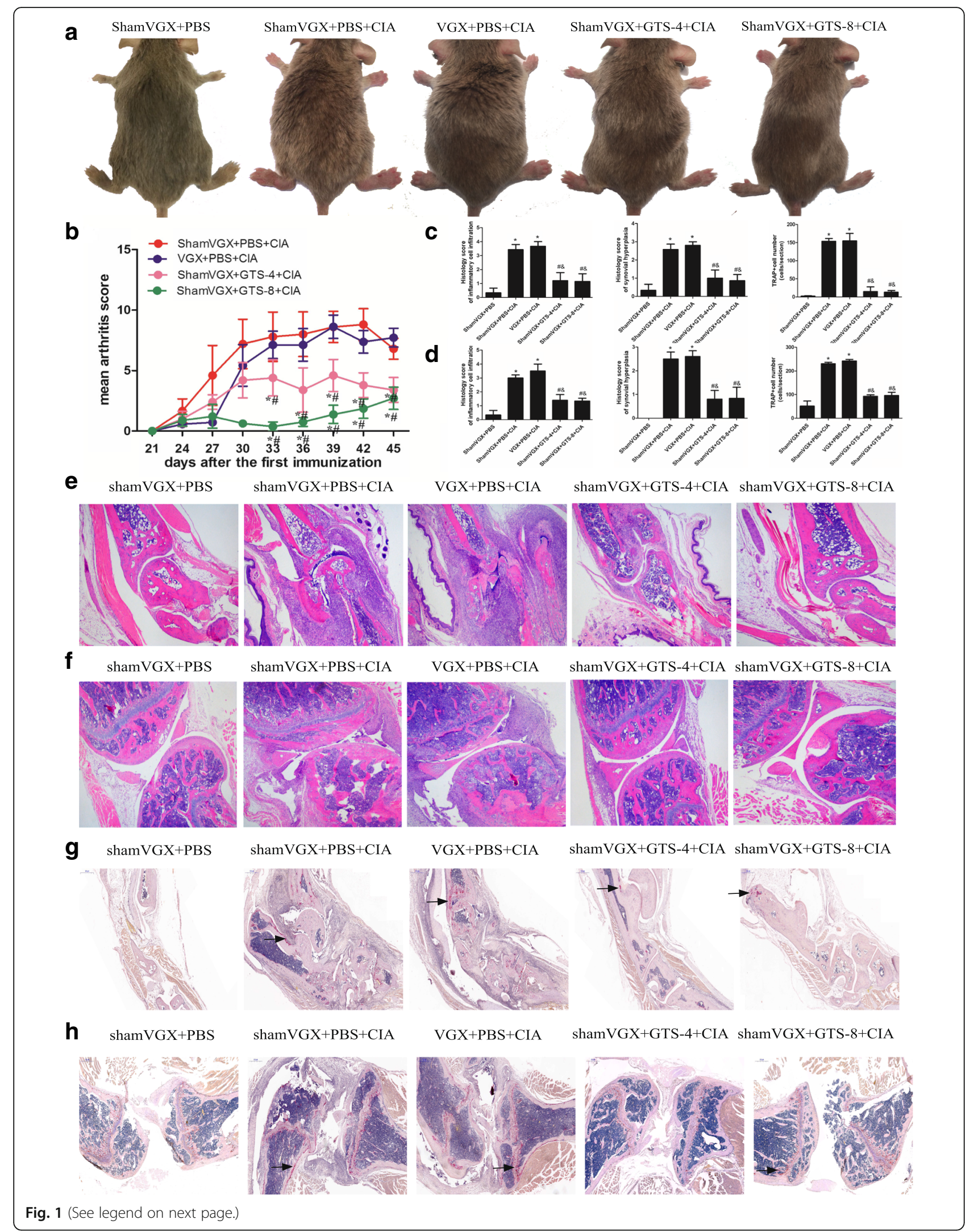


(See figure on previous page.)

Fig. 1 GTS-21 ameliorated inflammation in collagen-induced arthritis (CIA) mice. a The CIA model in DBA/1 mice was successfully established. GTS-21 decreased the redness and swelling of joints in CIA mice. $\mathbf{b}$ The arthritis score index was used to assess the severity of arthritis. GTS-21treated CIA mice showed a dramatic decrease in arthritis scores compared with those in mice in the model group and vagotomy group. $\mathbf{c}$ and $\mathbf{d}$ The score of inflammatory cell infiltration (grade $0-4$ ), synovial hyperplasia (grade $0-3$ ), and tartrate-resistant acid phosphatase-positive (TRAP ${ }^{+}$) cells in the ankle (c) and knee (d). e and $\mathbf{f}$ GTS-21 decreased the infiltration of inflammatory cells and synovial proliferation in the ankle (e, 40X) and knee $(f, 40 x)$ in CIA mice. $\mathbf{g}$ and $\mathbf{h}$ GTS-21 decreased the infiltration of osteoclasts in the ankle $(g, 40 x)$ and knee ( $h$, 40X) in CIA mice (the arrows point to TRAP $^{+}$cells). Data are expressed as the mean \pm standard deviation $(n=8)$. ${ }^{*} P<0.05$ versus the model group; ${ }^{\#} P<0.05$ versus the vagotomy group

treatment markedly decreased the levels of these cytokines. There was no significant difference in the level of IL-10 between the five groups (Fig. 2a-c).

\section{GTS-21 downregulates the surface molecules CD80 and MHC II in DCs in the spleen of CIA mice}

On day 45 after the first immunization, DBA/1 mice were humanely killed, and spleen single-cell suspensions were prepared. The expression of the co-stimulatory molecule CD80 and the antigen-presenting molecule MHC II on CD11 $\mathrm{c}^{+}$DCs was detected by using flow cytometry. The expression of CD80 and MHC II in DCs in the spleen was significantly higher in the CIA group and vagotomy group than in the control group, and treatment with GTS-21 (4 and $8 \mathrm{mg} / \mathrm{kg}$ ) significantly downregulated CD80 and MHC II expression compared with that in the model and vagotomy groups (Fig. 3).

\section{GTS-21 decreases DC infiltration into the synovium in CIA} mice

To further evaluate the effect of GTS-21 on DCs, the expression of the $\mathrm{DC}$-specific marker $\mathrm{CD} 11 \mathrm{c}$ was assessed in joint synovial tissues by immunohistochemistry. Few cells expressed CD11c in the control group. $\mathrm{CD} 11 \mathrm{c}$ expression was significantly upregulated in the model and vagotomy groups. GTS-21 downregulated $\mathrm{CD} 11 \mathrm{c}$ expression compared with that in the model and vagotomy groups (Fig. 4).

\section{GTS-21 inhibits BMDC differentiation}

To examine the direct effects of GTS-21 on DC differentiation, BMDCs were generated from C57BL/6 J mice. GTS-21 $(0.1,1,10$, or $100 \mu \mathrm{mol} / \mathrm{L})$ was added to BMDCs (except the control group) cultured under DC differentiation conditions. CD11c is a relatively specific marker for BMDCs, and F4/80 is considered a macrophage marker [32]. To ensure that BMDCs and CD11 $\mathrm{c}^{+}$ F4/80 ${ }^{-}$cells were gated (Additional file 1 ), within this population, the expression of CD80 and MHC II on DCs was measured with flow cytometry. The results showed that GTS-21 $(1,10$, or $100 \mu \mathrm{mol} / \mathrm{L})$ significantly inhibited the expression of the surface molecules MHC II (Fig. 5a and b) and CD80 (Fig. 5c and d) in DCs. The effect of GTS-21 $(10 \mu \mathrm{mol} / \mathrm{L})$ on inhibiting the expression of these molecules was significant and antagonized by the selective $\alpha 7 \mathrm{nAChR}$ antagonist methyllycaconitine (MLA) $(10 \mu \mathrm{mol} / \mathrm{L})$ (Fig. 5e-h).

GTS-21 has no obvious effect on BMDC maturation To induce BMDC maturation, lipopolysaccharide (LPS) $(1 \mu \mathrm{g} / \mathrm{mL})$ was added to BMDCs cultured under
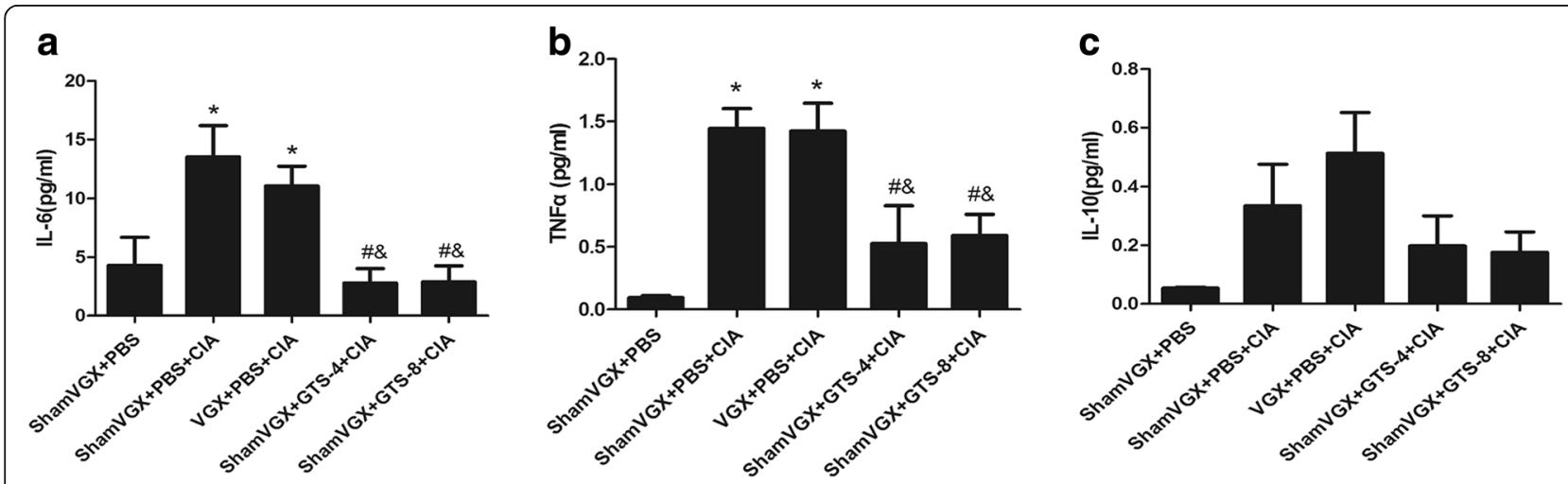

Fig. 2 Analysis of cytokine levels in the serum of DBA/1 mice. On day 45 after the initial immunization, the serum was collected. Luminex was used to detect the levels of tumor necrosis factor-alpha (TNF-a), interleukin-6 (IL-6), and IL-10. GTS-21 reduced the levels of IL-6(a) and TNF-a(b) but had no effect on IL-10. Data are expressed as the mean \pm standard deviation $(n=8)$. ${ }^{*} P<0.05$ versus the control group; ${ }^{\#} P<0.05$ versus the model group; ${ }^{\&} p<0.05$ versus the vagotomy group 


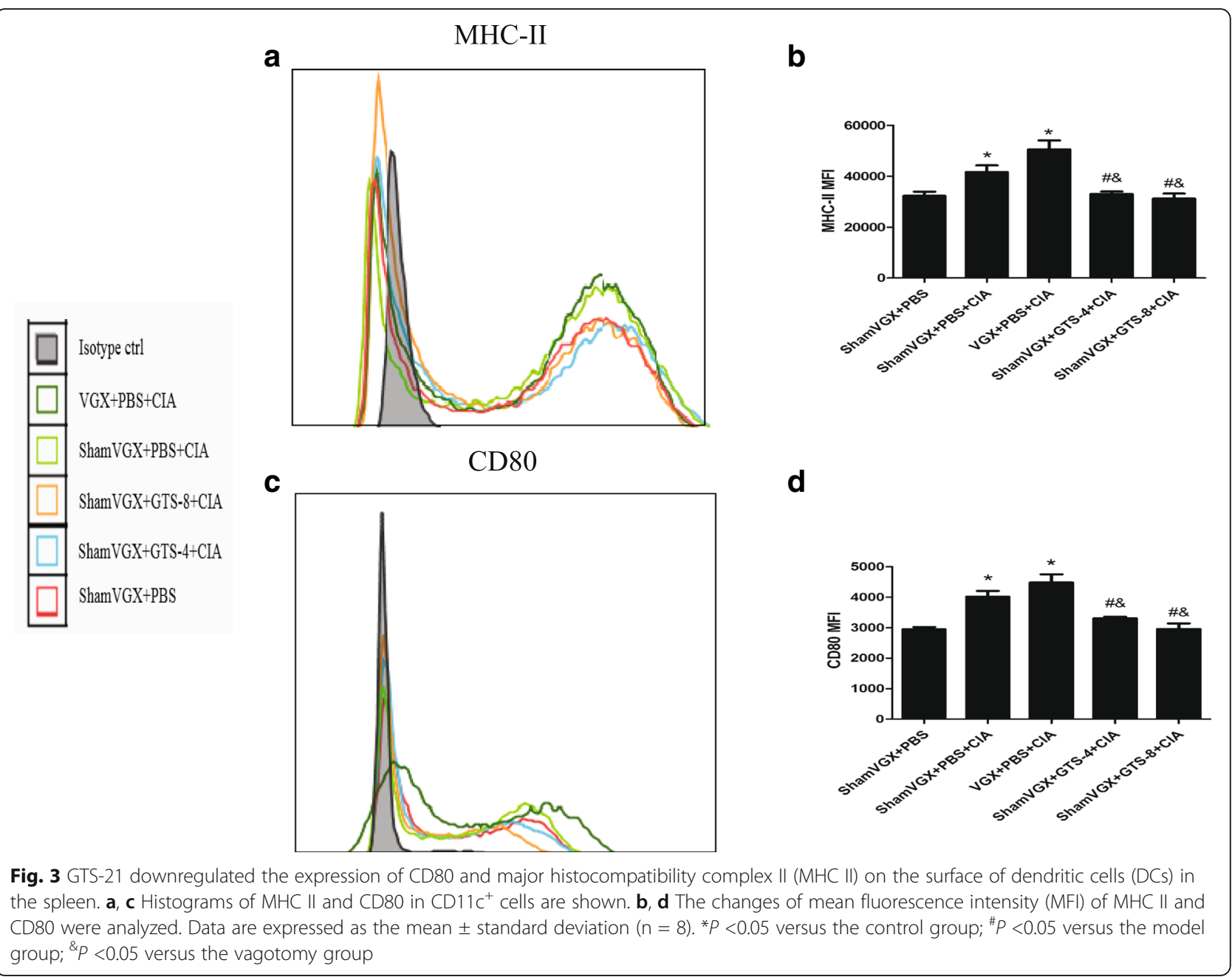

differentiation conditions on day 6. GTS-21 (0.1, 1, 10 , or $100 \mu \mathrm{mol} / \mathrm{L}$ ) was added to inhibit the maturation process. The expression of CD80 and MHC II on BMDCs was detected with flow cytometry on day 7. Compared with the BMDCs on day 6, LPS upregulated the expression of the surface molecules CD80 and MHC II, and GTS-21 had no obvious effect on CD80 and MHC II expression (Fig. 6).

\section{Discussions}

DCs are potent antigen-presenting cells that play a major role in the regulation of immune responses in RA. Rheumatoid synovial fluid and synovial tissues are enriched in mature DCs, which participate in the inflammatory cascade by secreting specific $\mathrm{T}$ cell-attracting chemokines and through the ongoing presentation of antigen to autoreactive $\mathrm{T}$ cells [33-35]. In animal models, administration of collagen-pulsed mature DCs is sufficient to induce arthritis [36]. This suggests that DCs are a valuable target for the management of RA. Here, we explored whether the anti-inflammatory pathway can prevent the development of RA through the modulation of DCs.

First, we investigated the effects of the cholinergic agonist GTS-21 on the pathogenesis of RA in a CIA model. Activation of the CAP with GTS-21 markedly reduced clinical arthritis, inflammatory cell infiltration, synovial hyperplasia, and bone damage. TNF- $\alpha$ and IL-6 are key pro-inflammatory cytokines in RA [37, 38]. Therefore, TNF $\alpha$ and IL- 6 levels were detected in the serum of CIA mice. The results showed that treatment with GTS-21 decreased the levels of the two cytokines. These data indicated that the CAP exerted strong anti-inflammatory effects in CIA mice. However, vagotomy did not exacerbate the inflammation in CIA mice, indicating that the contralateral vagus nerve may have a compensatory role. Further study is necessary to clarify this issue $[19,21]$. Moreover, a study showed that denervation protected limbs from arthritis using the $\mathrm{K} /$ $\mathrm{BxN}$ serum-transfer system by affecting the microvasculature [39]. More research is needed to explore the link between the nervous and immune systems. 


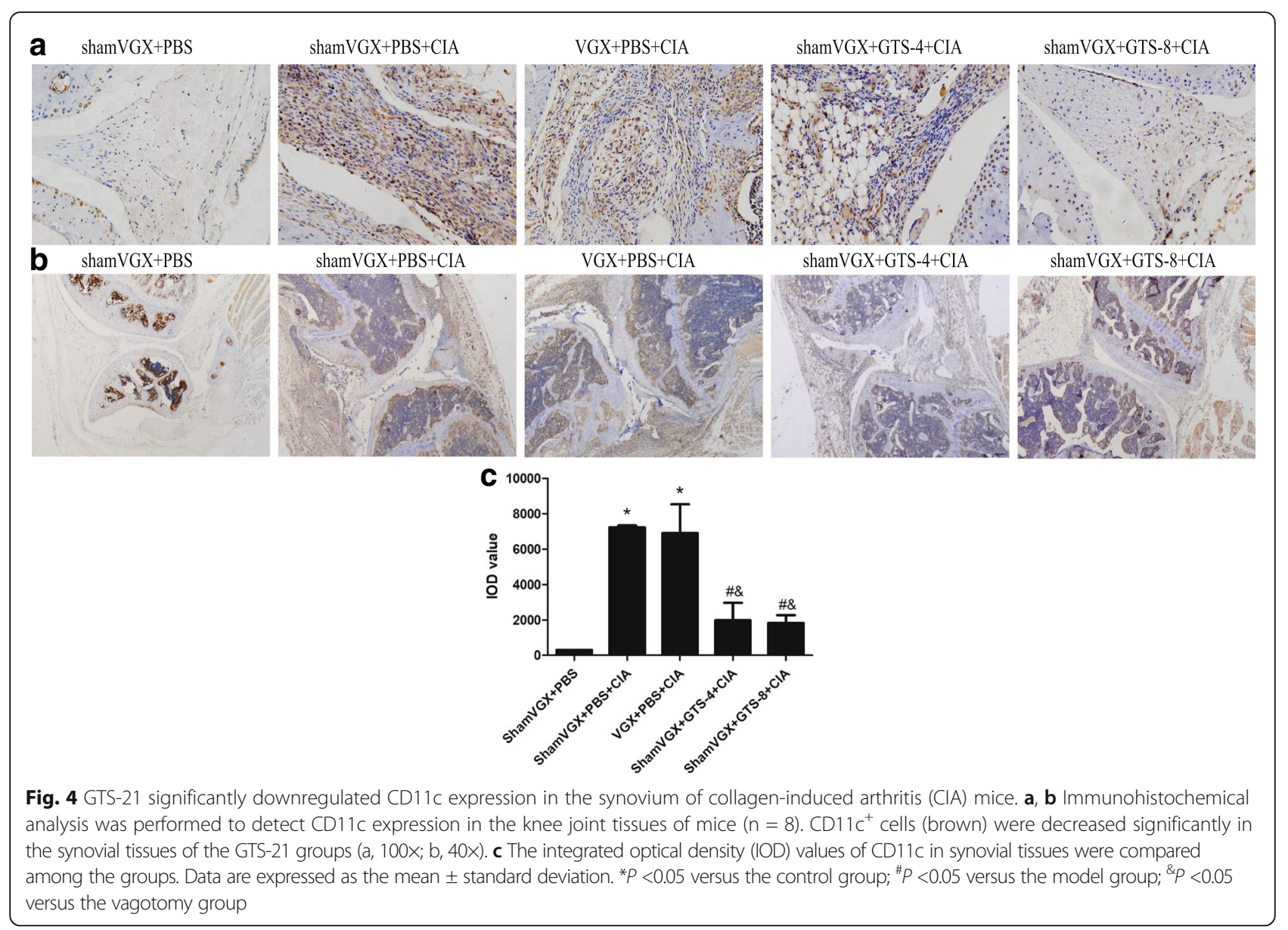

The immunologic mechanism underlying the effect of the CAP on protecting against CIA remains unclear. The results of this study demonstrated that the expression of the co-stimulatory molecules CD80 and MHC II in $\mathrm{CD}_{11 \mathrm{c}^{+}} \mathrm{DCs}$ in the spleen was upregulated in the CIA group, which is consistent with the results of a previous study [40]. We confirmed that DCs are involved in inflammation associated with CIA. GTS-21, a selective $\alpha 7 \mathrm{nAChR}$ agonist, has been used in clinical trials and is less toxic than nicotine $[41,42]$. GTS-21 $(4 \mathrm{mg} / \mathrm{kg}) \mathrm{sig}$ nificantly improves survival in murine models of endotoxemia, severe sepsis, and burns [43, 44]. Our data firstly confirmed the immunomodulatory effects of GTS- 21 on DCs in CIA mice. GTS-21 (4 and $8 \mathrm{mg} / \mathrm{kg}$ ) significantly downregulated the expression of MHC II and CD80 on the surface of DCs in the spleen of CIA mice. CD80 and MHC II are important surface molecules involved in the activation of Ag-specific $\mathrm{CD}_{4}^{+} \mathrm{T}$ cells [40], which suggests that the anti-inflammatory activity of the CAP in RA may be mediated, at least in part, by the modulation of DCs. CD11c is a relatively specific marker of DCs in mice $[45,46]$. The present results showed that $\mathrm{CD} 11 \mathrm{c}$ was upregulated in the joint synovium of CIA mice and that GTS-21 treatment downregulated
CD11c. This suggests that the anti-inflammatory pathway can directly affect the infiltration of DCs into the synovium.

DCs are derived from hematopoietic stem cells or peripheral blood mononuclear cells $[47,48]$. The expression of related specific markers such as HLA-DR on the surface of DCs increases during differentiation [49]. Immature DCs have a strong capacity for antigen uptake. Once activated, DCs are converted into mature DCs, which express high levels of the co-stimulatory molecules CD80/86 and the antigen-presenting molecule MHC II, and stimulate T-cell proliferation [50-52]. To determine whether GTS-21 suppressed the infiltration of DCs into the synovium by affecting DC differentiation or maturation, we performed a follow-up experiment. BMDCs were generated from mouse bone marrow progenitor cells through stimulation with GM-CSF and IL-4 in vitro [53], and LPS can induce the mutation of BMDCs. Our results showed that GTS-21 inhibited the differentiation of BMDCs from progenitor cells but had no effect on the maturation of BMDCs, which indicated that GTS-21 exerts an anti-inflammatory effect by inhibiting the differentiation of DCs. The effects of GTS-21 on BMDC differentiation were counteracted by the 


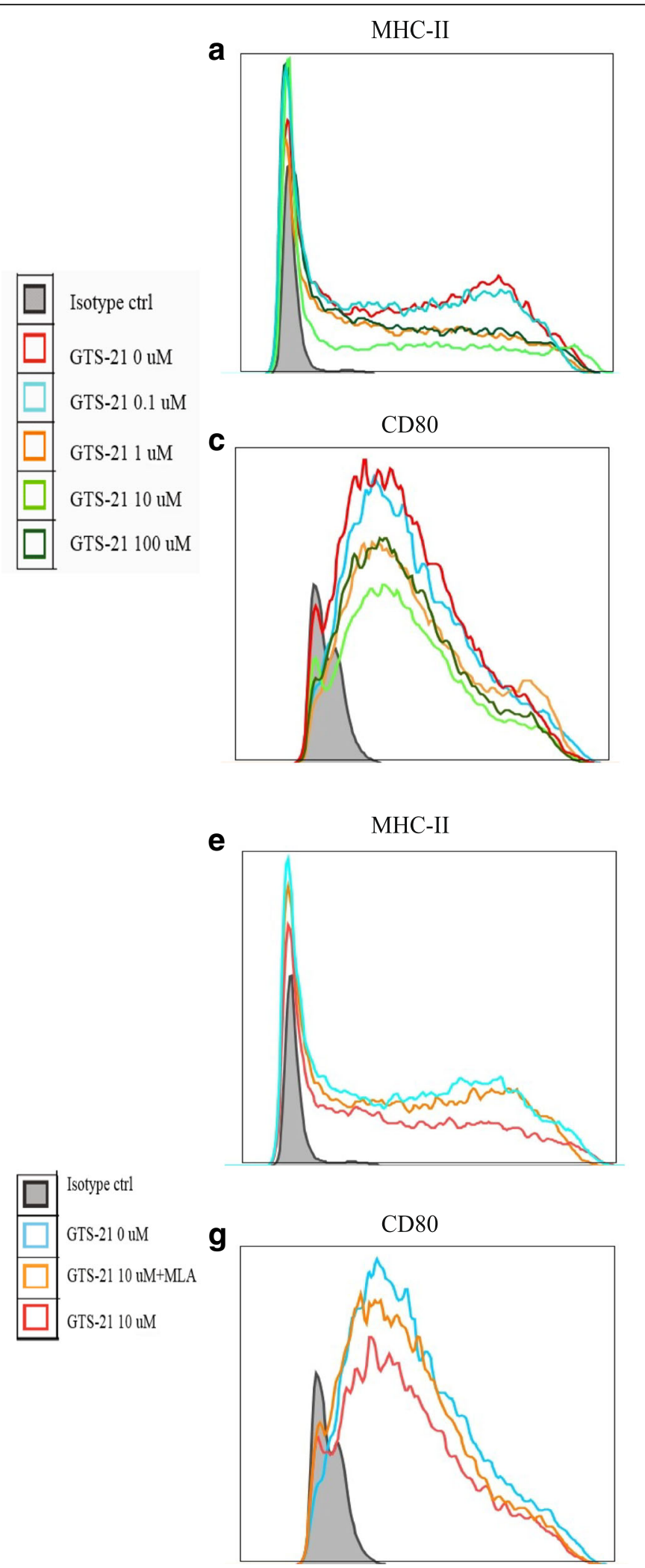

b

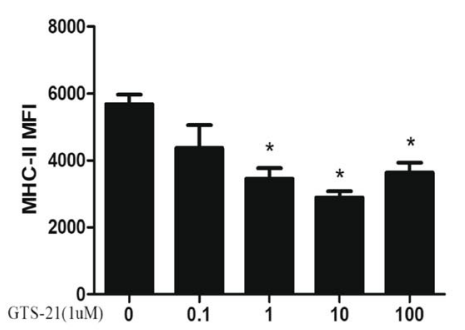

d

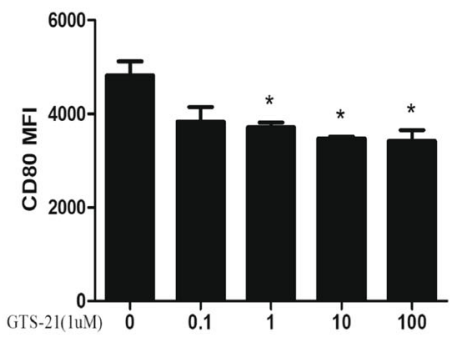

f

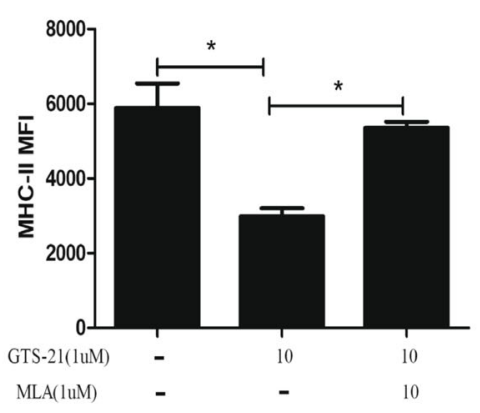

h

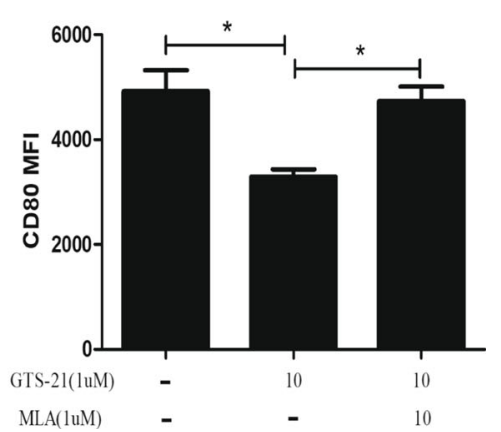

Fig. 5 (See legend on next page.) 
(See figure on previous page.)

Fig. 5 GTS-21 efficiently inhibited the expression of CD80 and major histocompatibility complex II (MHC II) on the surface of dendritic cells (DCs) during DC differentiation. Bone marrow-derived DCs were stimulated with GTS-21 (0.1, 1, 10, or $100 \mu \mathrm{mol} / \mathrm{L})$ for 6 days. The expression levels of MHC II and CD80 were detected by using flow cytometry. All data shown were gated on CD $11 \mathrm{C}^{+} \mathrm{F} 4 / 80^{-}$cells. $\mathbf{a}, \mathbf{c}, \mathbf{e}, \mathbf{g}$ Histograms of MHC II and CD80 in CD11 $\mathrm{C}^{+} \mathrm{F} 4 / 80^{-}$cells are shown. $\mathbf{b}, \mathbf{d}, \mathbf{f}, \mathbf{h}$ The changes of mean fluorescence intensity (MFI) of MHC II and CD80 were analyzed. (b, $d$ ) GTS-21 (1, 10, or $100 \mu \mathrm{mol} / \mathrm{L})$ decreased the MFI of CD80 and MHC II. (f, h) GTS-21 (10 $\mu \mathrm{mol} / \mathrm{L})$ significantly decreased the MFI of CD80 and MHC $\mathrm{II}$, and methyllycaconitine (MLA) reversed this effect. Data are expressed as the mean \pm standard deviation. ${ }^{*} P<0.05$ versus the control ("ctrl") group. All data are representative of three independent experiments

acetylcholine receptor antagonist MLA, confirming that GTS-21 affected DC differentiation by activating the $\alpha 7 \mathrm{nAchR}$.

The mechanism underlying the suppression of DCs by GTS-21 remains unclear. GM-CSF, a critical factor for DC development, can target multiple intracellular signaling pathways to affect DC differentiation, including the Janus kinase/signal transducer and activator of transcription (JAK/STAT) pathway, the mitogen-activated protein kinase (MAPK) pathway, and the phosphatidylinositol 3-kinase (PI3K) pathway [54]. Inhibition of JAK2/ STAT5, among these pathways, suppresses terminal DC differentiation [55, 56]. The MAPK and nuclear factor kappa-light-chain-enhancer of activated B cells (NF-kB) signaling pathways are involved in the maturation of DCs. Further experiments are needed to determine whether GTS-21 can regulate GM-CSF-related DC differentiation pathways.

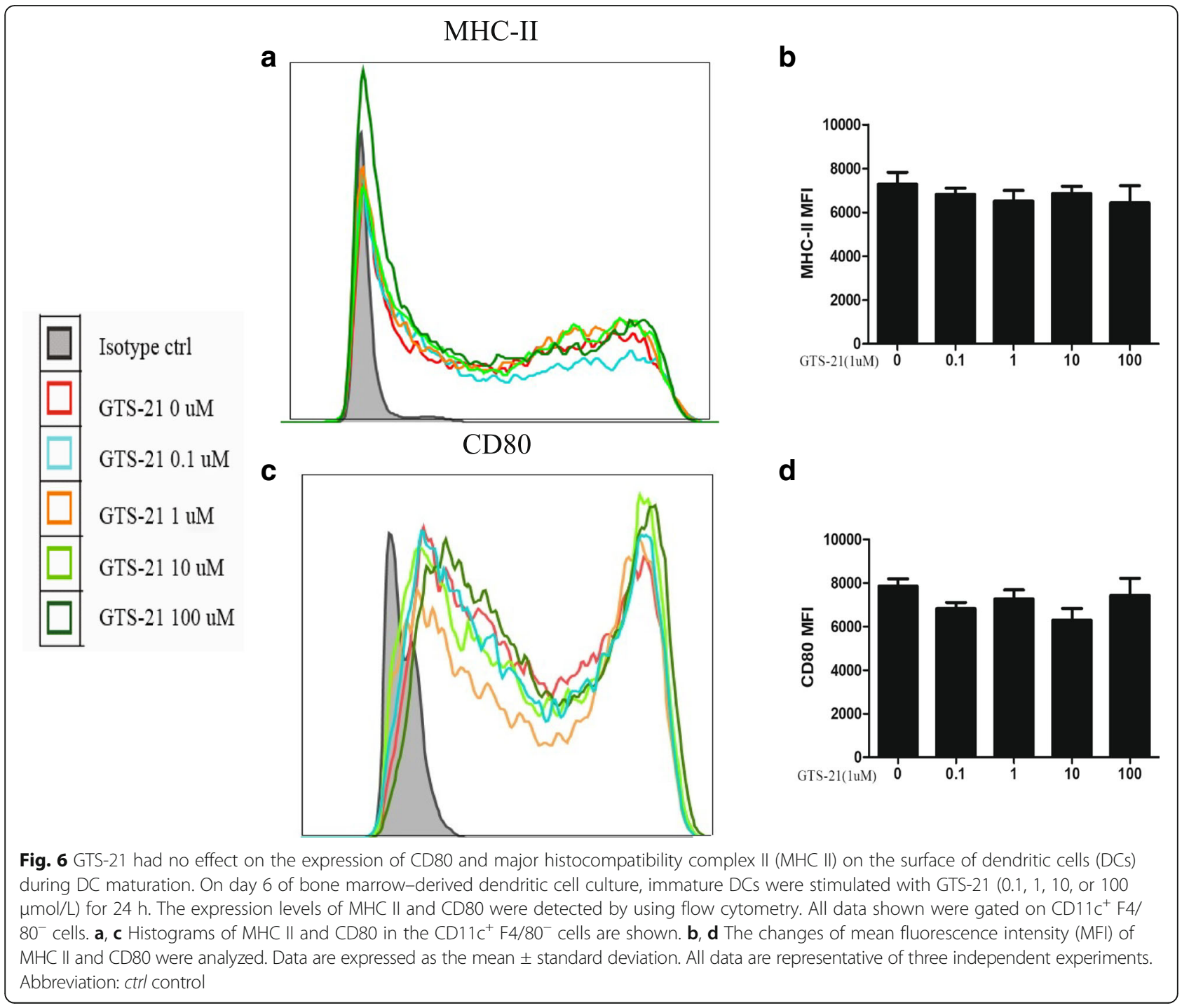




\section{Conclusions}

In summary, our research first investigated the anti-inflammatory effect of the cholinergic agonist GTS-21 on DCs in CIA. The present data indicated that GTS-21mediated activation of the CAP inhibited DC differentiation and ameliorated inflammation in a CIA model. These results may provide new insight into the immune regulatory mechanism underlying the activity of the CAP in RA.

\section{Additional file}

Additional file 1: Bone marrow-derived dendritic cells (BMDCs) were stained with antibodies against F4/80, CD11C, CD80 and major histocompatibility complex II (MHC II) and analyzed by flow cytometry.

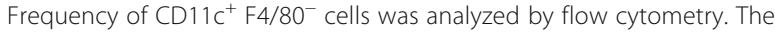
number in the upper right represents the percentage of $\mathrm{CD} 11 \mathrm{C}^{+} \mathrm{F} 4 / 80^{+}$ cells, which is less than $5 \%$. (DOCX $50 \mathrm{~kb}$ )

\section{Abbreviations}

a7nAChR: a7 subunit of the nicotinic acetylcholine receptor; BMDC: Bone marrow-derived dendritic cell; CAP: Cholinergic anti-inflammatory pathway; CIA: Collagen-induced arthritis; DC: Dendritic cell; GM-CSF: Granulocytemacrophage colony-stimulating factor; IL: Interleukin; IOD: Integrated optical density; JAK/STAT: Janus kinase/signal transducer and activator of transcription; LPS: Lipopolysaccharide; MAPK: Mitogen-activated protein kinase; MHC II: Major histocompatibility complex II; MLA: Methyllycaconitine; PBS: Phosphate-buffered saline; RA: Rheumatoid arthritis; rmGM-CSF: Recombinant mouse granulocytemacrophage colony-stimulating factor; TNFa: Tumor necrosis factor-alpha; TRAP: Tartrate-resistant acid phosphatase; VGX: Vagotomy

\section{Acknowledgments}

We would like to thank all members of the Department of Rheumatology and Immunology, Xiangya Hospital, Central South University.

\section{Funding}

This work was supported by grants from the National Natural Science Foundation of China $(81501854,81571602)$ and the Fundamental Research Funds for the Central Universitiesof Central South University (2018zzts284).

\section{Availability of data and materials}

The datasets supporting the conclusions of this article are included within the article.

\section{Authors' contributions}

DL contributed to performing experiments, analyzing data, and writing the manuscript. TL, HL, and XZ interpreted data and contributed to writing the manuscript. SL and SW designed the research, interpreted data, and contributed to writing the manuscript. All authors read and approved the final version of the manuscript.

\section{Ethics approval}

All animal experimental procedures in the current study were approved by the Institutional Animal Care and Use Committee of Xiangya Hospital, Central South University (Changsha, China).

\section{Consent for publication}

Not applicable.

\section{Competing interests}

The authors declare that they have no competing interests.

\section{Publisher's Note}

Springer Nature remains neutral with regard to jurisdictional claims in published maps and institutional affiliations.
Received: 27 July 2018 Accepted: 31 October 2018

Published online: 28 November 2018

\section{References}

1. Mclnnes IB, Schett $G$. The pathogenesis of rheumatoid arthritis. N Engl J Med. 2011;365:2205-19.

2. Kubo S, Yamaoka K, Kondo M, Yamagata K, Zhao J, Iwata S, et al. The JAK inhibitor, tofacitinib, reduces the $T$ cell stimulatory capacity of human monocyte-derived dendritic cells. Ann Rheum Dis. 2014;73:2192-8.

3. Stoop JN, Robinson JH, Hilkens CM. Developing tolerogenic dendritic cell therapy for rheumatoid arthritis: what can we learn from mouse models? Ann Rheum Dis. 2011;70:1526-33.

4. Leal Rojas IM, Mok WH, Pearson FE, Minoda Y, Kenna TJ, Barnard RT, et al. Human Blood CD1c(+) Dendritic Cells Promote Th1 and Th17 Effector Function in Memory CD4(+) T Cells. Front Immunol. 2017:8:971.

5. Murphy CA, Langrish CL, Chen Y, Blumenschein W, McClanahan T, Kastelein RA, et al. Divergent pro- and antiinflammatory roles for IL-23 and IL-12 in joint autoimmune inflammation. J Exp Med. 2003;198:1951-7.

6. Miossec P. Dynamic interactions between T cells and dendritic cells and their derived cytokines/chemokines in the rheumatoid synovium. Arthritis Res Ther. 2008;10(Suppl 1):S2.

7. Walsh KP, Mills KH. Dendritic cells and other innate determinants of $\mathrm{T}$ helper cell polarisation. Trends Immunol. 2013;34:521-30.

8. Khan S, Greenberg JD, Bhardwaj N. Dendritic cells as targets for therapy in rheumatoid arthritis. Nat Rev Rheumatol. 2009;5:566-71.

9. Ning B, Wei J, Zhang A, Gong W, Fu J, Jia T, et al. Antigen-specific tolerogenic dendritic cells ameliorate the severity of murine collageninduced arthritis. PLoS One. 2015;10:e0131152.

10. Yang J, Yang Y, Fan H, Zou H. Tolerogenic splenic IDO (+) dendritic cells from the mice treated with induced-Treg cells suppress collagen-induced arthritis. J Immunol Res. 2014;2014:831054.

11. Thome R, Fernandes LG, Mineiro MF, Simioni PU, Joazeiro PP, Tamashiro WM. Oral tolerance and OVA-induced tolerogenic dendritic cells reduce the severity of collagen/ovalbumin-induced arthritis in mice. Cell Immunol. 2012:280:113-23.

12. Schinnerling K, Soto L, Garcia-Gonzalez P, Catalan D, Aguillon JC. Skewing dendritic cell differentiation towards a tolerogenic state for recovery of tolerance in rheumatoid arthritis. Autoimmun Rev. 2015;14:517-27.

13. Hilkens CM, Isaacs JD. Tolerogenic dendritic cell therapy for rheumatoid arthritis: where are we now? Clin Exp Immunol. 2013;172:148-57.

14. Bell GM, Anderson AE, Diboll J, Reece R, Eltherington O, Harry RA, et al. Autologous tolerogenic dendritic cells for rheumatoid and inflammatory arthritis. Ann Rheum Dis. 2017;76:227-34.

15. Inoue T, Tanaka S, Okusa MD. Neuroimmune Interactions in Inflammation and Acute Kidney Injury. Front Immunol. 2017;8:945.

16. Pavlov VA, Wang H, Czura CJ, Friedman SG, Tracey KJ. The cholinergic antiinflammatory pathway: a missing link in neuroimmunomodulation. Mol Med. 2003:9:125-34.

17. Koopman FA, Vosters JL, Roescher N, Broekstra N, Tak PP, Vervoordeldonk MJ. Cholinergic anti-inflammatory pathway in the non-obese diabetic mouse model. Oral Dis. 2015;21:858-65.

18. Ren C, Tong YL, Li JC, Lu ZQ, Yao YM. The Protective Effect of Alpha 7 Nicotinic Acetylcholine Receptor Activation on Critical IIIness and Its Mechanism. Int J Biol Sci. 2017;13:46-56.

19. van Maanen MA, Lebre MC, van der Poll T, LaRosa GJ, Elbaum D, Vervoordeldonk MJ, et al. Stimulation of nicotinic acetylcholine receptors attenuates collagen-induced arthritis in mice. Arthritis Rheum. 2009;60:114-122

20. Zhou Y, Zuo X, Li Y, Wang Y, Zhao H, Xiao X. Nicotine inhibits tumor necrosis factor-alpha induced IL-6 and IL-8 secretion in fibroblast-like synoviocytes from patients with rheumatoid arthritis. Rheumatol Int. 2012;32:97-104.

21. Li S, Zhou B, Liu B, Zhou Y, Zhang H, Li T, et al. Activation of the cholinergic anti-inflammatory system by nicotine attenuates arthritis via suppression of macrophage migration. Mol Med Rep. 2016;14:5057-64.

22. Wu S, Luo H, Xiao X, Zhang H, Li T, Zuo X. Attenuation of collagen induced arthritis via suppression on Th17 response by activating cholinergic antiinflammatory pathway with nicotine. Eur J Pharmacol. 2014;735:97-104.

23. Wu S, Zhao H, Luo H, Xiao X, Zhang H, Li T, et al. GTS-21, an alpha7nicotinic acetylcholine receptor agonist, modulates Th1 differentiation in CD4(+) T cells from patients with rheumatoid arthritis. Exp Ther Med. 2014;8:557-62. 
24. Li T, Zuo X, Zhou Y, Wang $Y$, Zhuang $H$, Zhang $L$, et al. The vagus nerve and nicotinic receptors involve inhibition of HMGB1 release and early proinflammatory cytokines function in collagen-induced arthritis. J Clin Immunol. 2010;30:213-20.

25. Munyaka P, Rabbi MF, Pavlov VA, Tracey KJ, Khafipour E, Ghia JE. Central muscarinic cholinergic activation alters interaction between splenic dendritic cell and CD4+CD25- T cells in experimental colitis. PLoS One. 2014;9:e109272.

26. Camps M, Ruckle T, Ji H, Ardissone V, Rintelen F, Shaw J, et al. Blockade of PI3Kgamma suppresses joint inflammation and damage in mouse models of rheumatoid arthritis. Nat Med. 2005;11:936-43.

27. Greenhill CJ, Jones GW, Nowell MA, Newton Z, Harvey AK, Moideen AN, et al. Interleukin-10 regulates the inflammasome-driven augmentation of inflammatory arthritis and joint destruction. Arthritis Res Ther. 2014;16:419.

28. Ding HB, Liu KX, Huang JF, Wu DW, Chen JY, Chen QS. Protective effect of exogenous hydrogen sulfide on pulmonary artery endothelial cells by suppressing endoplasmic reticulum stress in a rat model of chronic obstructive pulmonary disease. Biomed Pharmacother. 2018;105:734-41.

29. Tang $Y$, Cai $Q H$, Wang YJ, Fan SH, Zhang ZF, Xiao MQ, et al. Protective effect of autophagy on endoplasmic reticulum stress induced apoptosis of alveolar epithelial cells in rat models of COPD. Biosci Rep. 2017;37.

30. Miah MA, Yoon CH, Kim J, Jang J, Seong YR, Bae YS. CISH is induced during DC development and regulates DC-mediated CTL activation. Eur J Immunol. 2012;42:58-68

31. Inaba K, Inaba M, Romani N, Aya H, Deguchi M, Ikehara S, et al. Generation of large numbers of dendritic cells from mouse bone marrow cultures supplemented with granulocyte/macrophage colony-stimulating factor. J Exp Med. 1992;176:1693-702

32. Chen L, Wang S, Wang Y, Zhang W, Ma K, Hu C, et al. IL-6 influences the polarization of macrophages and the formation and growth of colorectal tumor. Oncotarget. 2018;9:17443-54.

33. Thomas R, Davis LS, Lipsky PE. Rheumatoid synovium is enriched in mature antigen-presenting dendritic cells. J Immunol. 1994;152:2613-23.

34. Thomas R, Quinn C. Functional differentiation of dendritic cells in rheumatoid arthritis: role of CD86 in the synovium. J Immunol. 1996;156: 3074-86.

35. Moret FM, Hack CE, van der Wurff-Jacobs KM, de Jager W, Radstake TR, Lafeber FP, et al. Intra-articular CD1c-expressing myeloid dendritic cells from rheumatoid arthritis patients express a unique set of T cell-attracting chemokines and spontaneously induce Th1, Th17 and Th2 cell activity. Arthritis Res Ther. 2013;15:R155.

36. Leung BP, Conacher M, Hunter D, McInnes IB, Liew FY, Brewer JM. A novel dendritic cell-induced model of erosive inflammatory arthritis: distinct roles for dendritic cells in T cell activation and induction of local inflammation. J Immunol. 2002;169:7071-7.

37. Burska A, Boissinot M, Ponchel F. Cytokines as biomarkers in rheumatoid arthritis. Mediat Inflamm. 2014;2014:545493.

38. Myers LK, Rosloniec EF, Cremer MA, Kang AH. Collagen-induced arthritis, an animal model of autoimmunity. Life Sci. 1997;61:1861-78.

39. Stangenberg L, Burzyn D, Binstadt BA, Weissleder R, Mahmood U, Benoist C, et al. Denervation protects limbs from inflammatory arthritis via an impact on the microvasculature. Proc Natl Acad Sci U S A. 2014;111:11419-24.

40. Wu H, Chen J, Song S, Yuan P, Liu L, Zhang Y, et al. beta2-adrenoceptor signaling reduction in dendritic cells is involved in the inflammatory response in adjuvant-induced arthritic rats. Sci Rep. 2016:6:24548.

41. Nanri M, Kasahara N, Yamamoto J, Miyake H, Watanabe H. A comparative study on the effects of nicotine and GTS-21, a new nicotinic agonist, on the locomotor activity and brain monoamine level. Jpn J Pharmacol. 1998;78:385-9.

42. Meyer EM, Kuryatov A, Gerzanich V, Lindstrom J, Papke RL. Analysis of 3-(4hydroxy, 2-Methoxybenzylidene)anabaseine selectivity and activity at human and rat alpha-7 nicotinic receptors. J Pharmacol Exp Ther. 1998;287:918-25.

43. Pavlov VA, Ochani M, Yang LH, Gallowitsch-Puerta M, Ochani K, Lin X, et al. Selective alpha7-nicotinic acetylcholine receptor agonist GTS-21 improves survival in murine endotoxemia and severe sepsis. Crit Care Med. 2007;35:1139-44.

44. Khan MAS, Khan MF, Kashiwagi S, Kem WR, Yasuhara S, Kaneki M, et al. An ALPHA7 Nicotinic Acetylcholine Receptor Agonist (GTS-21) Promotes C2C12 Myonuclear Accretion in Association with Release of Interleukin-6 (IL-6) and Improves Survival in Burned Mice. Shock. 2017:48:227-35.

45. Ahmed MS, Byeon SE, Jeong Y, Miah MA, Salahuddin M, Lee Y, et al. Dab2, a negative regulator of DC immunogenicity, is an attractive molecular target for DC-based immunotherapy. Oncoimmunology. 2015;4:e984550.
46. Li X, Han Y, Zhou Q, Jie H, He Y, Han J, et al. Apigenin, a potent suppressor of dendritic cell maturation and migration, protects against collageninduced arthritis. J Cell Mol Med. 2016;20:170-80.

47. Gabrilovich D. Mechanisms and functional significance of tumour-induced dendritic-cell defects. Nat Rev Immunol. 2004;4:941-52.

48. Moretto MM, Lawlor EM, Khan IA. Aging mice exhibit a functional defect in mucosal dendritic cell response against an intracellular pathogen. J Immunol. 2008;181:7977-84.

49. Satpathy AT, Wu X, Albring JC, Murphy KM. Re(de)fining the dendritic cell lineage. Nat Immunol. 2012;13:1145-54.

50. Dumortier $H$, van Mierlo GJ, Egan D, van Ewijk W, Toes RE, Offringa R, et al. Antigen presentation by an immature myeloid dendritic cell line does not cause CTL deletion in vivo, but generates CD8+ central memory-like T cells that can be rescued for full effector function. J Immunol. 2005;175:855-63.

51. Amigorena S. Fc gamma receptors and cross-presentation in dendritic cells. J Exp Med. 2002;195:F1-3.

52. Kufer $P$, Zettl F, Borschert K, Lutterbuse R, Kischel R, Riethmuller G. Minimal costimulatory requirements for $\mathrm{T}$ cell priming and $\mathrm{TH} 1$ differentiation: activation of naive human $T$ lymphocytes by tumor cells armed with bifunctional antibody constructs. Cancer Immun. 2001;1:10.

53. Palucka K, Banchereau J. Dendritic-cell-based therapeutic cancer vaccines. Immunity. 2013;39:38-48.

54. van de Laar L, Coffer PJ, Woltman AM. Regulation of dendritic cell development by GM-CSF: molecular control and implications for immune homeostasis and therapy. Blood. 2012;119:3383-93.

55. Esashi E, Wang YH, Perng O, Qin XF, Liu YJ, Watowich SS. The signal transducer STAT5 inhibits plasmacytoid dendritic cell development by suppressing transcription factor IRF8. Immunity. 2008;28:509-20.

56. van de Laar $L$, van den Bosch $A$, Wierenga AT, Janssen HL, Coffer PJ, Woltman AM. Tight control of STAT5 activity determines human CD34-derived interstitial dendritic cell and langerhans cell development. J Immunol. 2011; 186:7016-24.

\section{Ready to submit your research? Choose BMC and benefit from:}

- fast, convenient online submission

- thorough peer review by experienced researchers in your field

- rapid publication on acceptance

- support for research data, including large and complex data types

- gold Open Access which fosters wider collaboration and increased citations

- maximum visibility for your research: over $100 \mathrm{M}$ website views per year

At BMC, research is always in progress.

Learn more biomedcentral.com/submissions 